\title{
Evolution of choroidal thickness over time and effect of early and sustained therapy in birdshot retinochoroiditis
}

N Skvortsova ${ }^{1,2}$, A Gasc 1 , B Jeannin' ${ }^{1}$ and CP Herbort ${ }^{1,3}$

\begin{abstract}
Purpose To follow choroidal thickness (ChT) over time in birdshot retinochoroiditis (BRC) using enhanced depth imaging optical coherence tomography (EDI-OCT) and study the effect of early and sustained treatment on ChT.

Patients and methods Eighteen patients were included and EDI-OCT measurements of ChT were analyzed retrospectively in five groups of patients with follow-up times ranging from 1 year to $\geq 15$ years. The OCT images were evaluated and ChT was calculated under the foveola and $1500 \mu \mathrm{m}$ temporal, nasal, superior, and inferior to the foveola. To assess the effect of treatment, 13 patients with a disease duration $\geq \mathbf{1 0}$ years were divided into two groups depending on their treatment status: early and sustained therapy $v s$ insufficient, late, or no treatment. ChT was compared in these two groups along with the number of typical fundus BRC lesions.

Results The ChT decreased ( $r=-0.41$, $P=0.0018)$ over the disease duration, which ranged from $<1$ year to $\geq 15$ years. In patients with a disease duration $\geq 10$ years, a significant difference in ChT was noted between adequately and undertreated patients $(288.3 \pm 76.9 \mu \mathrm{m}$ vs $161.4 \pm 39.2 \mu \mathrm{m}$; $P=0.004)$. At the last follow-up, in the group with insufficient therapy 10 of 11 eyes presented typical fundus BRC lesions vs 2 of 13 eyes in the treated group $(P \leq 0.0006$,

F-test).

Conclusions Choroidal thickness decreases significantly over time in BRC. If undertreated, patients show thinner choroids compared with adequately treated individuals and present significantly more BRC lesions.

Eye (2017) 31, 1205-1211; doi:10.1038/eye.2017.54; published online 21 April 2017
\end{abstract}

\section{Introduction}

Birdshot retinochoroiditis (BRC) is a rare bilateral autoimmune uveitis, with no apparent systemic involvement, which mostly occurs in Caucasians. ${ }^{1}$ It was first described in 1980 by Ryan and Maumenee, who named it $^{2}$ and nearly concomitantly by Gass, who called the disease vitiliginous choroiditis. ${ }^{3}$ The typical clinical appearance of the full-blown disease is characterized by low, often subclinical anterior segment inflammation, vitritis, retinal vasculitis involving large veins as well as small retinal capillaries, ${ }^{4}$ and rice-shaped hypopigmented choroidal lesions (BRC lesions). ${ }^{5}$ We now know that when PCR is used for detection, the HLAA29 antigen is present in almost $100 \%$ of cases and has to be considered a required diagnostic criterion. Indeed, HLA-A29 negative cases are extremely rare. ${ }^{6-10}$ The availability of indocyanine green angiography (ICGA) is another factor that also changed our appraisal of BRC, as it can provide precise information on choroidal inflammatory involvement. Most importantly, this method makes it possible to detect disease activity in the choroid before it becomes clinically evident by the appearance of BRC lesions. As a result, more appropriate diagnostic criteria have been put forward, allowing early diagnosis of BRC. ${ }^{11}$ These include the presence of vitritis and retinal vasculitis in one or both eyes, visual field anomalies in one or both eyes, stromal choroiditis as evidenced by ICGA in both eyes (required), HLA-A29 antigen positivity (required), and the absence of extra-ocular inflammation sites. The presence of BRC lesions is also strongly suggestive of BRC but not requested anymore. ${ }^{11}$

BRC is unique in producing dual independent inflammatory involvement of the choroid and retina, with the latter being responsible for disease morbidity and functional impairment due
${ }^{1}$ Retinal and Inflammatory Eye Diseases, Centre for Ophthalmic Specialised Care, Lausanne, Switzerland

${ }^{2}$ Posterior Eye Segment Diagnostics and Surgery Center, Moscow, Russia

${ }^{3}$ University of Lausanne, Lausanne, Switzerland

Correspondence: CP Herbort, Retinal and Inflammatory Eye Diseases, Centre for Ophthalmic Specialized Care (COS), Rue Charles-Monnard 6, Lausanne CH-1003, Switzerland Tel: +41216431512 E-mail: cph@herbortuveitis.ch

Received: 2 November 2016 Accepted in revised form: 9 February 2017 Published online: 21 April 2017 
to inflammatory damage. ${ }^{1,12}$ Retinal involvement has been studied using both fluorescein angiography (FA) and optical coherence tomography (OCT). Main FA signs in early exudative disease include: retinal capillary leakage with diffuse retinal edema involving the macula but less prominent in the fovea, leakage along large veins seen in late frames, and disc hyperfluorescence. ${ }^{1}$ At a later stage of disease, FA shows diffuse thinning of vessels, including arteries and veins, a consequence of extensive atrophic retinal thinning, which can be partially avoided by early and sustained inflammation suppressive treatment (IST). ${ }^{1}$

Optical coherence tomography is another approach for examining retinal disease and provides a morphological explanation for the retinal signs observed by FA. We showed that in early disease, a diffusely thickened retina was measured in the macula, although less so in the fovea, which exhibited fewer fluctuations in thickness during disease progression. ${ }^{13}$ This supports the FA finding that the fovea was relatively spared and that visual acuity remained relatively conserved until late in the disease. After a few years of disease progression, OCT revealed areas of atrophy/thinning and thickening; while in late disease, the mean retinal thickness was reduced (mostly in patients for which IST had been delayed). ${ }^{13}$ Since the 1990s, the choroid can be explored by ICGA, which made it possible to assess and monitor inflammatory choroidal involvement in BRC by allowing detection of occult choroidal lesions that were otherwise inaccessible. ${ }^{14}$ Relevant ICGA signs for the diagnosis and disease monitoring are the presence of hypofluorescent dark dots (HDDs) caused by stromal inflammatory foci, and fuzzy large choroidal vessels, indicating vasculitis. ${ }^{15}$

In recent years, there has been substantial interest in using enhanced depth imaging optical coherence tomography (EDI-OCT) to potentially replace ICGA for monitoring choroiditis. ${ }^{16}$ The EDI-OCT is a non-invasive tool that can investigate the choroidal space, with the capability to image deeper choroidal structures, enabling quantitative measurements of choroidal thickness. ${ }^{17}$ The disadvantage of EDI-OCT, or other choroidal OCT devices that image deep choroidal structures, is their inability to examine global pan-fundal choroidal inflammation; thus, they cannot provide panoramic information comparable to that generated by ICGA. ${ }^{18,19}$ It was shown that EDI-OCT, unlike ICGA, was not suited for precise and close visit-to-visit monitoring of choroiditis during the acute phase of stromal choroiditis when therapeutic adjustment was crucial; ${ }^{20}$ however, it might become a useful method for the long-term followup of stromal choroiditis such as BRC. ${ }^{21}$ The aim of this study was to investigate the long-term evolution of choroidal thickness in BRC patients and to verify whether early and sustained IST management had a significant impact on the evolution of choroidal thickness.

\section{Materials and methods}

\section{Patients}

We surveyed 1793 cases of uveitis treated at the Centre for Ophthalmic Specialized Care, Lausanne, Switzerland, from 1995 to 2015 and retrieved all charts with the diagnosis of BRC. For this study, we included all patients for whom the EDI-OCT data were available. Patients were subdivided into five groups according to the disease duration-group 1: non-treated initial disease $(<1$ year since the first occurrence of symptoms), group 2: patients with 1-4 years of evolution, group 3: patients with 5-9 years of evolution, group 4: patients with 10-14 years of evolution, and group 5: patients with $\geq 15$ years of evolution. The exclusion criteria were as follows: (1) high myopia or hyperopia (more than 6 diopters), (2) the presence or history of choroidal neovascularization secondary to BRC, (3) substantial media opacities affecting visual acuity (that is, cataract) and the quality of OCT-scans, and (4) a history of other retinal or choroidal diseases. Patients with long follow-up periods, when applicable, could be included in subsequent groups. The study was performed in accordance with the ethical standards laid down in the 1964 Declaration of Helsinki.

\section{Diagnosis and treatment}

The diagnosis of BRC was performed in accordance with previously published diagnostic criteria. ${ }^{11}$ Briefly, the diagnosis of BRC was defined as: retinal vasculitis in large or small veins in one or both eyes; vitritis in one or both eyes; visual field abnormalities in one or both eyes; ICGA lesions in both eyes (required); and the presence of HLAA29 antigen (required), with or without oval, depigmented, birdshot lesions (BRC lesions). Adequate treatment was defined as follows: treatment within 1 year after the occurrence of first symptoms with systemic or sub-Tenon's steroids associated with immunosuppressants, mostly mycophenolic acid (Myfortic), cyclosporine, or azathioprine, and corticosteroids being tapered to 0 or to $<7.5 \mathrm{mg}$ per day. In case of insufficient recovery of visual fields and/or the persistence of retinal or choroidal inflammatory signs (monitored by FA and ICGA), a second immunosuppressant or biologic agent was added (for example, anti-TNF- $\alpha$ treatment). Treatment was maintained indefinitely.

\section{Outcome measures}

In this study, the primary outcomes were as follows: (1) the assessment of choroidal thickness evolution over time and (2) in patients having a follow-up of $\geq 10$ years, a comparison of choroidal thickness for those who received 
early and sustained IST vs untreated patients or patients treated insufficiently or late (undertreated group). Secondary outcomes compared in these two groups included the best-corrected visual acuity (BCVA), the visual field data (mean defect-MD), and the presence or absence of BRC lesions at the last follow-up.

\section{Clinical work-up}

All patients underwent the routine complete work-up for patients with uveitis, including a Snellen visual acuity test, slit-lamp examination, applanation tonometry and fundoscopy, laser flare photometry (Kowa FM-500 or FM-700 laser flaremeter, Kowa Co., Tokyo, Japan), computerized visual field testing, enhanced depth imaging optical coherence tomography (EDI-OCT), and dual fluorescein and ICGA (the latter not reported in this study). Visual field assessment was performed with a G1Program, OCTOPUS 900 (Octopus 900, G Standard; Haag-Streit, Bern, Switzerland).

\section{EDI-OCT}

The EDI-OCT scans were obtained using a Heidelberg Spectralis OCT (Heidelberg Engineering Inc., Heidelberg, Germany). Choroidal thickness was measured manually on EDI scans under the foveola and $1500 \mu \mathrm{m}$ temporal (T), nasal (N), superior (S), and inferior (I) to the foveola. Choroidal thickness measurements were performed perpendicular to the retinal pigmentary epithelium (RPE), going from the posterior RPE edge to the choroid-scleral junction. The mean thickness was established by calculating the mean value of six measurements (under the foveola and at $1500 \mu \mathrm{m} \mathrm{T,} \mathrm{N} \mathrm{for} \mathrm{the} \mathrm{horizontal} \mathrm{three}$ scans and under the foveola and at $1500 \mu \mathrm{m} \mathrm{I}, \mathrm{S}$ for the vertical three scans; mean of six values in total for each eye measured). Evaluation of OCT scans and measurements of choroidal thickness were conducted by the same experienced observer (AG) and checked in a blinded manner by an additional trained observer (BJ). Difference in choroidal thickness (baseline visit minus final visit) was normalized to the baseline visit measurement. Rate of choroidal thinning was set as difference in choroidal thickness divided by the number of months between baseline and final follow-up visit.

\section{Statistical analysis}

The descriptive statistics used were the median and 95\% confidence interval (CI) and the mean and SD. The MannWhitney $U$ test was used to compare the data in two independent groups with abnormal distribution of data. The multiple comparison of ChT in five groups was tested by Analysis of Variation (ANOVA) with post hoc
Bonferroni correction. The difference in the presence of BRC lesions was estimated using two-tailed Fisher's exact test. The degree of correlation was evaluated by Pearson correlation coefficient and Spearman correlation coefficient. The inter-observer variation was assessed using the intraclass correlation coefficient. Statistical significance was set at $P<0.05$. Analysis was performed using MedCalc (version 15.2 for Windows; MedCalc Software; Ostend, Belgium) and SPSS software version 23 (SPSS, Inc, Chicago, IL, USA).

\section{Results}

\section{Demographics and clinical and functional data}

Of the 1793 new cases of uveitis seen at the Centre for Ophthalmic Specialized Care, Lausanne, Switzerland, from 1995 to 2015, 29 (1.61\%) had the diagnosis of BRC. Among those patients, EDI-OCT data were available for 18 patients (10 women and 8 men). The median age at disease onset was 57 years (95\% CI: 51.5-62.5 years) (range: $41-80$ years). In all patients, the human leucocyte histocompatibility antigen HLA-A29 was present (100\%). In the 13 patients with a follow-up of 10 years or more, seven patients were considered to have received adequate treatment and six were undertreated. Mean BCVA at presentation was $0.96 \pm 0.27$ (range: 0.05 (amblyopia)1.25). Visual field alterations (MD) at presentation was $7.75 \pm 7.16 \mathrm{~dB}$ (range: -1.1 to $24.9 \mathrm{~dB}$ ). Visual acuity did not show statistically significant correlation with disease duration $(P=0.55)$, while MD of visual field had a low degree correlation with the duration of BRC $(r=0.28$, $P=0.05)$. Mean laser flare photometry values amounted to $7.47 \pm 6.04 \mathrm{ph} / \mathrm{ms}$ (range: $4.4-22.5 \mathrm{ph} / \mathrm{ms}$ ), indicating only subclinical anterior segment inflammation.

Significant vitritis was observed at presentation in 6 of 18 cases (Diagnostic Criteria from Standardization of Uveitis Nomenclature).

\section{Evolution of choroidal thickness (EDI-ChT) over time}

The intraclass correlation coefficient was $0.921(P=0.001)$, showing a high reliability in inter-observers' manual measurements. When analyzing all patients, choroidal thickness decreased over time $(r=-0.41, P=0.0018)$. In the group with initial onset, untreated disease with $<1$ year duration of symptoms, the EDI-ChT was $375 \pm 141 \mu \mathrm{m}$ (No. of eyes $=6$, mean time of evolution $=3.3 \pm 2.3$ months), while it was $281 \pm 120 \mu \mathrm{m}$ (No. of eyes $=6$, mean time of evolution $=3.3 \pm 0.6$ years) in group 2 (1-4 years of disease evolution), $249 \pm 69.7 \mu \mathrm{m}$ (No. of eyes $=10$; mean time of evolution $=7.8 \pm 1.5$ years) in group 3 (5-9 years of evolution), $254 \pm 75.6 \mu \mathrm{m}$ (No. of eyes $=16$; mean time of evolution $=11.9 \pm 1.3$ years $)$ in 
group 4 (10-14 years of evolution), and $209 \pm 84.5 \mu \mathrm{m}$ (No. of eyes $=17$ eyes, mean time of evolution $=16.8 \pm 3.2$ years) in group 5 ( $\geq 15$ years of evolution). A repeated measures ANOVA determined that mean ChT differed statistically significantly between 5 groups $(\mathrm{F}=3.783$, $P=0.009$ ). Post hoc tests using the Bonferroni correction revealed the decrease of ChT during the disease duration. The decrease of ChT was statistically significant between group 1 and group $5(P=0.004)$, whereas, it was statistically insignificant among other groups. The evolution of EDI-ChT is shown in Figure 1.

\section{Comparison of EDI-ChT in adequately treated vs undertreated patients with $\geq 10$ years of evolution}

Thirteen patients had an EDI-OCT performed after 10 or more years of disease evolution (mean disease evolution $13.7 \pm 3.7$ years (range: $10-21$ years). The clinical data of patients are summarized in Table 1. Thirteen eyes (seven patients) received early sustained systemic treatment starting $<1$ year after initial symptoms, and eleven eyes (six patients) did not receive any treatment (three patients) or received delayed treatment (that is, $\geq 3$ years after the initial symptoms) or insufficient treatment (three patients). There were no significant differences in age, sex, disease duration, and refractive error between the two groups (Table 2). The mean choroidal thickness in the treated group was $288.3 \pm 76.9 \mu \mathrm{m}$, while it was $161.4 \pm 39.2 \mu \mathrm{m}(P \leq 0.0001)$ in the undertreated group (Figure 2). The average choroidal thinning for both groups was $1.30 \mu \mathrm{m}$ per month. Representative examples of choroidal thickness from each group are shown in Figures $3 a$ and $b$.

A slightly lower BCVA was measured in the undertreated group, compared with the treated group (mean $0.8 \pm 0.2$ vs $1.0 \pm 0.3, P \leq 0.0055)$. Visual field

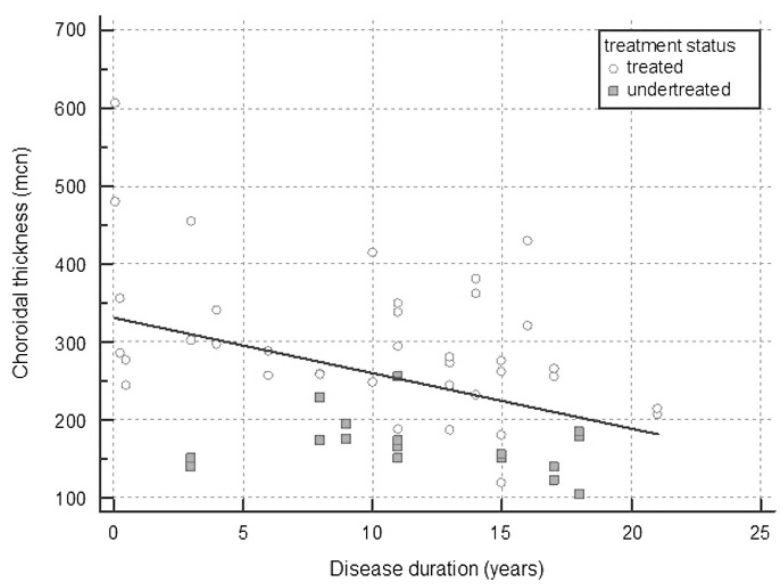

Figure 1 Graph showing the evolution of choroidal thickness during disease duration. deterioration was less important in the treated group. The MD values were $4.4 \pm 2.7 \mathrm{~dB}$ in the treated group and $8.6 \pm 8.5 \mathrm{~dB}$ in the undertreated group. However, the difference did not reach statistical significance because of the small samples and the large standard deviations. In the group with early and sustained treatment, only 2 of 13 eyes showed typical fundus BRC lesions at the last followup, while 10 of 11 eyes with late or no treatment presented typical BRC lesions (Figures $3 \mathrm{c}$ and d), a highly statistically significant finding $(P \leq 0.00006$, two-tailed F-test).

\section{Discussion}

Birdshot retinochoroiditis is a chronic bilateral uveitis affecting the retina and choroid. Presently, OCT visualization enables clinicians to investigate the choroid for better appraisal of the disease. Even though choroidal thickness is affected by sex, age, axial length, ${ }^{22}$ and systemic medications, several reports showed a significant decrease in the choroidal thickness in patients with BRC compared with healthy individuals. ${ }^{23-25}$ Our results are in agreement with previous short-term studies; in this study, a substantial decrease of choroidal thickness was noted in patients from disease onset to the long period of disease evolution ( $>15$ years). We hypothesize that the decrease of choroidal thickness is related to the choroidal atrophy developed following the resolution of choroidal inflammation. The same finding was observed in another inflammatory disease affecting the choroidVogt-Koyanagi-Harada (VKH) disease. ${ }^{18,21}$ Unlike to $\mathrm{BRC}, \mathrm{VKH}$ is more widespread and, consequently, more studied. The typical sunset glow fundus appearance as a result of undertreatment is associated with thinner choroids compared to healthy controls. ${ }^{18}$

In addition to determining the progression of choroidal thinning over time, our purpose was to investigate whether early and sustained therapy had a long-term effect in preventing thinning of the choroid. The importance of early and sustained therapy has been put forward previously by showing that it could prevent the development of BRC lesions, changing the classical phenotype of BRC. ${ }^{26}$ The typical 'atrophic' BRC lesions occur in the choroid and represent areas devoid of choroidal pigment after the inflammatory reaction against it has subsided. It would be logical that less lesions would translate into less global choroidal atrophy. Indeed, patients with BRC treated aggressively had significantly less choroidal thinning in comparison with undertreated patients. The mean choroidal thickness in the early and sustained treatment group was maintained at $288.3 \pm 76.9 \mu \mathrm{m}$, a fairly normal choroidal thickness. ${ }^{22,27}$ The difference in monthly choroidal thinning was statistically insignificant for both groups and amounted to 
Table 1 Clinical data of patients with disease durations $\geq 10$ years

\begin{tabular}{|c|c|c|c|c|c|c|c|c|}
\hline \multirow[t]{2}{*}{ Patient } & \multirow[t]{2}{*}{ Age (years) } & \multirow[t]{2}{*}{ Gender } & \multirow[t]{2}{*}{ Disease duration (years) } & \multirow[t]{2}{*}{ Treatment } & \multicolumn{2}{|c|}{$B C V A$} & \multicolumn{2}{|c|}{$\begin{array}{c}\text { Typical BRC } \\
\text { lesions }\end{array}$} \\
\hline & & & & & $O D$ & OS & $O D$ & OS \\
\hline 1 & 63 & M & 10 & Adequate & 1 & $0.05^{\mathrm{a}}$ & No & No \\
\hline 2 & 65 & $\mathrm{~F}$ & 11 & Adequate & 1 & 1.25 & No & No \\
\hline 3 & 57 & M & 11 & Adequate & Excluded & 0.8 & No & No \\
\hline 4 & 60 & $\mathrm{~F}$ & 11 & Adequate & 1.25 & 1.25 & No & No \\
\hline 5 & 65 & $\mathrm{~F}$ & 14 & Adequate & 1.25 & 1.25 & No & No \\
\hline 6 & 63 & $\mathrm{~F}$ & 13 & Adequate & 1.25 & 1.25 & No & No \\
\hline 7 & 70 & $\mathrm{~F}$ & 21 & Adequate & 1 & 1 & Yes & Yes \\
\hline 8 & 72 & $\mathrm{~F}$ & 11 & Late/Insufficient therapy & 1 & 0.7 & Yes & Yes \\
\hline 9 & 70 & $\mathrm{~F}$ & 11 & Late/Insufficient therapy & 0.4 & 1 & Yes & Yes \\
\hline 10 & 80 & $\mathrm{~F}$ & 12 & None & 0.5 & 0.7 & No & Yes \\
\hline 11 & 77 & M & 18 & None & Excluded & 0.8 & Yes & Yes \\
\hline 12 & 70 & M & 19 & None & 1 & 1 & Yes & Yes \\
\hline 13 & 60 & M & 17 & Late/Insufficient therapy & 0.9 & 0.6 & Yes & Yes \\
\hline
\end{tabular}

Abbreviation: BCVA, best-corrected visual acuity. ${ }^{\text {a }} \mathrm{SD}=$ Amblyopia.

Table 2 Demographics and clinical data for the treated and undertreated groups

\begin{tabular}{lcc}
\hline & $\begin{array}{c}\text { Treated group } \\
(13 \text { eyes })^{\mathrm{a}}\end{array}$ & $\begin{array}{c}\text { Undertreated } \\
\text { group }(11 \text { eyes })^{a}\end{array}$ \\
\hline Age, years & $63.3 \pm 6.9$ & $71.5 \pm 6.9$ \\
Sex (M/F) & $4 / 3$ & $3 / 3$ \\
Disease duration, years & $13 \pm 3.7$ & $14.6 \pm 3.7$ \\
Refractive error, D & $+0.25 \pm 2.0$ & $-0.75 \pm 1.25$ \\
\hline
\end{tabular}

All the data are presented as the mean $\pm \mathrm{SD}$. ${ }^{\mathrm{a}}$ One eye excluded in each group because of myopia $>6$ diopters.

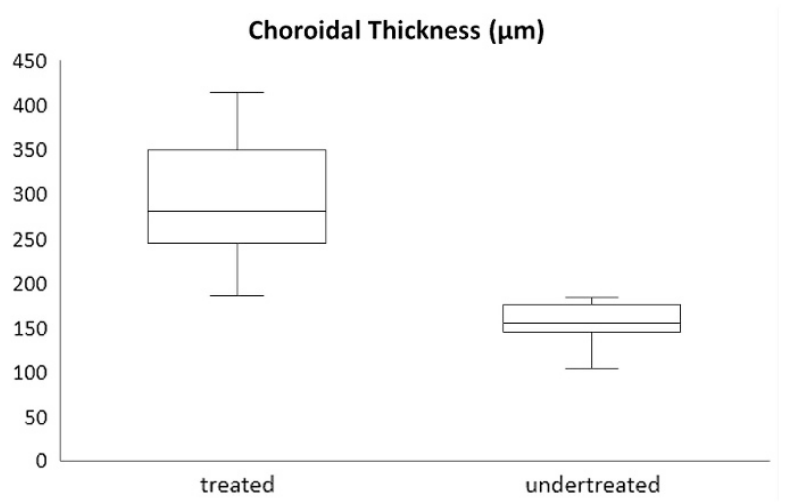

Figure 2 Graph showing the difference in choroidal thickness $(\mu \mathrm{m})$ between the adequately treated and undertreated group.

$1.30 \mu \mathrm{m}$ that was less than $2.68 \mu \mathrm{m}$ previously reported..$^{24}$ This finding can be explained by disease duration: the choroid thinning occurs with a greater rate in first years of BRC and after 10 years from disease onset, the choroidal thickness decreases with the same rate in treated and undertreated patients. We speculate that early treatment leads to choroidal preservation in the first 10 years of the disease. Additionally, in contrast to adequately treated patients, at the last follow-up, the presence of typical BRC lesions was noted in 10 of 11 undertreated eyes, while only 2 of 13 eyes in treated patients had such lesions at this moment. In the undertreated group, BCVA was not substantially diminished, confirming that visual acuity is not a good functional parameter to monitor disease progression. The functional deterioration in the undertreated group should probably be linked with retinal morbidity caused by a less well controlled retinal inflammatory process in the undertreated group. ${ }^{10}$ This hypothesis is supported by our previous study on retinal OCT analysis. ${ }^{13}$

The limitations of our study are the small number of patients, which is a problem inherent to such a rare disease, as well as its retrospective nature. Considering the previous reports on OCT findings in BRC, there were 2 more specific limitations: the lack of refractive error information and the analysis of EDI-ChT without correlation with treatment status. ${ }^{23,24}$ There are no standard criteria for OCT analysis in patients with choroidal inflammation; moreover, the absence of a detailed protocol, which includes the difference of various OCT instruments and software does not bring clarity and make an issue for carrying out a multicenter study. However, in this single-center study, we showed that choroidal thickness is related not only to the disease duration but also to the treatment status and should be considered an additional important parameter for the long-term follow-up of BRC. These choroidal OCT findings add to the progress of quantitative methods for evaluating posterior uveitis. Furthermore, our results represent an additional argument in favor of early and sustained treatment for BRC. ${ }^{26,28}$ 


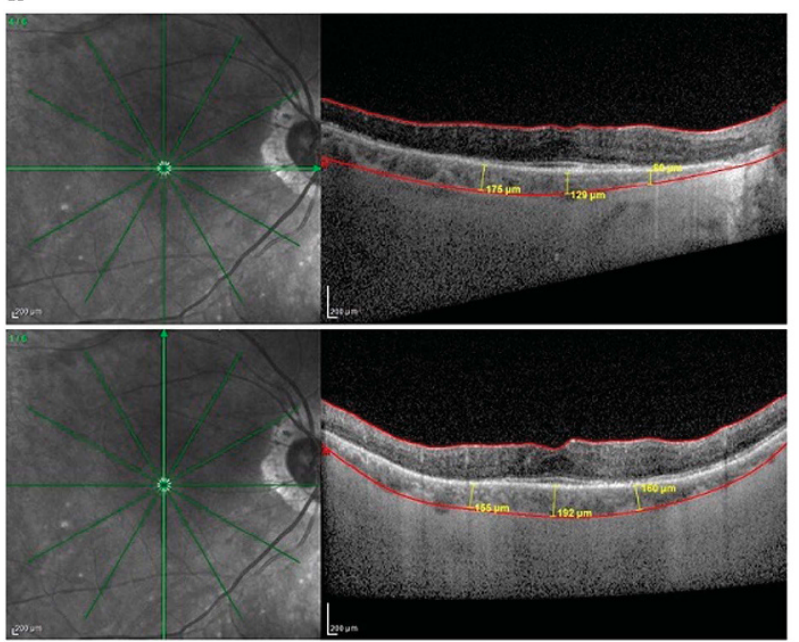

C

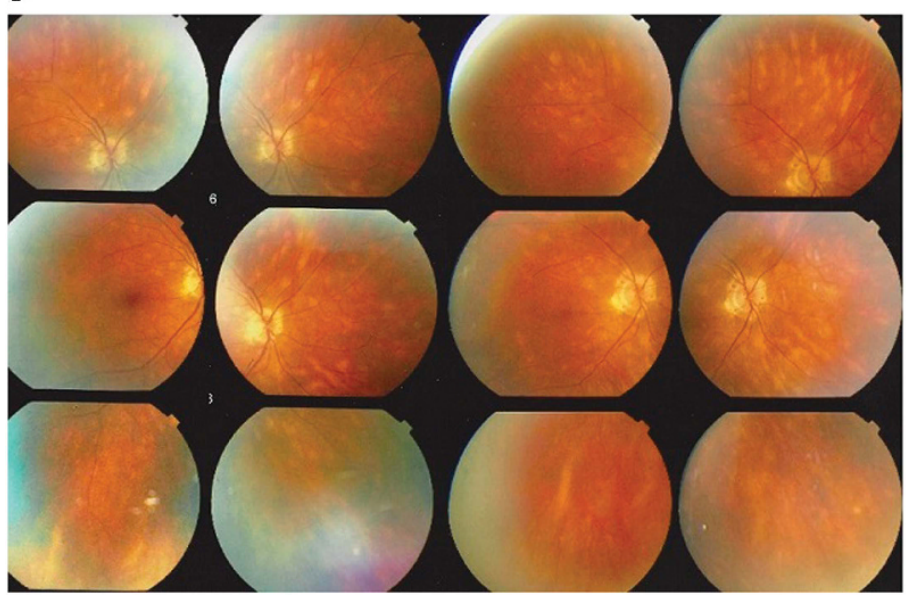

b

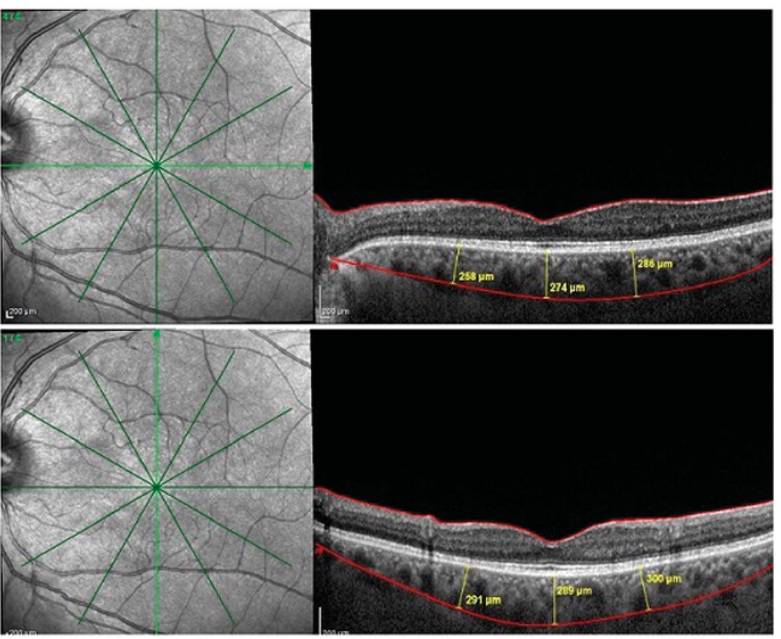

d

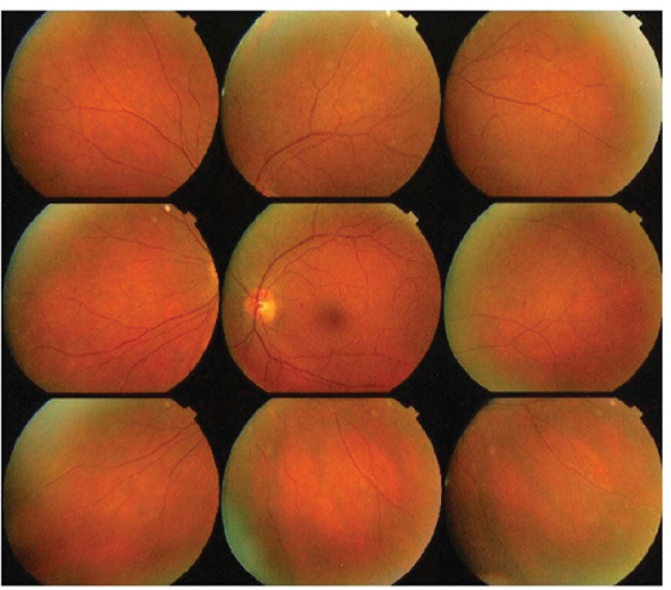

Figure 3 (a) EDI-OCT measurement of choroidal thickness (top-horizontal and bottom-vertical) in an undertreated patient with a disease evolution of 13 years, showing a much thinner choroid of $148.5 \pm 39.6 \mu \mathrm{m}$. (b) EDI-OCT measurement of choroidal thickness (top-horizontal and bottom-vertical) in an adequately treated patient with a disease evolution of 11 years, showing a conserved thickness of $283 \pm 14.6 \mu \mathrm{m}$. (c) Fundus photography of an undertreated patient with a disease evolution of 13 years (same patient as in section 'a') with numerous typical BRC lesions. (d) Fundus photography of an adequately treated patient with a disease evolution of 11 years (same patient as in section ' $b$ ') with an absence of typical BRC lesions.

\section{Summary}

\section{What was known before}

- EDI-OCT measurement of choroidal thickness in birdshot retinochoroiditis (BRC) has been reported in two articles in 2015 (11 patients) and in 2016 (8 patients), which both showed decreased thickness in comparison to choroid of healthy individuals.

\section{What this study adds}

- Thickness was put in relation with treatment and it was shown that choroid is significantly thinner in undertreated patients. Patients adequately treated and conserved choroidal thickness presented significantly less BRC fundus lesions.

\section{Conflict of interest}

The authors declare no conflict of interest.

\section{References}

1 Papadia M, Herbort CP. Reappraisal of birdshot retinochoroiditis (BRC): a global approach. Graefes Arch Clin Exp Ophthalmol 2013; 251: 861-869.

2 Ryan SJ, Maumenee AE. Birdshot retinochoroidopathy. Am J Ophthalmol 1980; 89: 31-45.

3 Gass JDM. Vitiliginous chorioretinitis. Arch Ophthalmol 1981; 99: 1778-1787. 
4 Guex-Crosier Y, Herbort CP. Prolonged retinal arteriovenous circulation time by fluorescein but not by indocyanine green angiography in birdshot chorioretinopathy. Ocul Immunol Inflamm 1997; 5: 203-206.

5 Gasch AT, Smith JA, Whitcup SM. Birdshot retinochoroidopathy. Br J Ophthalmol 1999; 83: 241-249.

6 Nussenblatt RB, Mittal KK, Ryan S, Green WR, Maumenee AE. Birdshot retinochoroidopathy associated with HLA-A29 antigen and immune responsiveness to retinal S-antigen. Am J Ophthalmol 1982; 94: 147-158.

7 Baarsma GS, Priem HA, Kijlstra A. Association of birdshot retinochoroidopathy and HLA-A29 antigen. Curr Eye Res 1990; 9: 63-68.

8 LeHoang P, Osdemir N, Benhamou A, Tabary T, Edelson C, Betuel $\mathrm{H}$ et al. HLA-A29.2 subtype associated with birdshot retinochoroidopathy. Am J Ophthalmol 1992; 113: 33-35.

9 Brezin AP, Monnet D, Cohen JH, Levinson RD. HLA-A29 and birdshot chorioretinopathy. Ocul Immunol Inflamm 2011; 19: $397-400$

10 Wender JD, Fu AD, Jumper JM, McDonald HR, Johnson RN, Cunningham ET Jr. False-negative antibody-based HLA-A29 typing in two patients with birdshot chorioretinopathy. Br J Ophthalmol 2008; 92: 1153-1154.

11 Papadia M, Herbort CP Jr. New concepts in the appraisal and management of birdshot retinochoroiditis: a global perspective. Int Ophthalmol 2015; 35: 287-301.

12 Herbort CP, Probst K, Cimino L, Tran VT. Differential inflammatory involvement in retina and choroid in birdshot chorioretinopathy. Klin Monbl Augenheilkd 2004; 221: 351-356.

13 Papadia M, Jeannin B, Herbort CP. OCT findings in birdshot chorioretinitis: a glimpse into retinal disease evolution. Ophthalmic Surg Lasers Imaging 2012; 43(Suppl): 25-31.

14 Fardeau C, Herbort CP, Kullmann N, Quentel G, LeHoang P. Indocyanine green angiography in birdshot chorioretinopathy. Ophthalmology 1999; 106: 1928-1934.

15 Herbort CP, Mantovani A, Papadia M. Use of indocyanine green angiography in uveitis. Int Ophthalmol Clin 2012; 52: 13-31.

16 Chee SP, Chan SN, Jap A. Comparison of enhanced depth imaging and swept source optical coherence tomography in assessment of choroidal thickness in Vogt-Koyanagi-Harada disease. Ocul Immunol Inflamm 2016; 12: 1-5.

17 Spaide RF, Koisumi H, Posonni MC. Enhanced depth imaging spectral-domain optical coherence tomography. Am J Ophthalmol 2008; 146: 496-500.

18 Nakai K, Gomi F, Ikuno Y, Yasuno Y, Nouchi T, Ohguro N et al. Choroidal observation in Vogt-Koyanagi-Harada disease using high penetration optical coherence tomography. Graefes Arch Clin Exp Ophthalmol 2012; 250: 1089-1095.

19 Nagiel A, Sadda SR, Sarraf D. A promising future for optical coherence tomography angiography. JAMA Ophthalmol 2015; 133: 629-630.
20 Balci O, Gasc A, Jeannin B, Herbort CP Jr. Enhanced depth imaging is less suited than indocyanine green angiography for close monitoring of primary stromal choroiditis: a pilot study. Int Ophthalmol 2016; e-pub ahead of print 2 August 2016; doi:10.1007/s10792-016-0303-7.

21 Jap A, Chee SP. The role of enhanced depth imaging optical coherence tomography in chronic Vogt-Koyanagi-Harada disease. Br J Ophthalmol 2016; 101: 186-189.

22 Abbey AM, Kuriyan AE, Modi YS, Thorell MR, Nunes RP, Goldhardt R et al. Optical coherence tomography measurements of choroidal thickness in healthy eyes: correlation with age and axial length. Ophthalmic Surg Lasers Imaging Retina 2015; 46: 18-24.

23 Silpa-Archa S, Maleki A, Roohipoor R, Preble JM, Foster CS. Analysis of three-dimensional choroidal volume with enhanced depth imaging findings in patients with birdshot retinochoroidopathy. Retina 2016; 36: 1758-1766.

24 Young M, Fallah N, Forooghian F. Choroidal degeneration in birdshot chorioretinopathy. Retina 2015; 35: 798-802.

25 Keane PA Allie M, Turner SJ, Southworth HS, Sadda SR, Murray PI et al. Characterization of birdshot chorioretinopathy using extramacular enhanced depth optical coherence tomography. JAMA Ophthalmol 2013; 131: 341-350.

26 Knecht PB, Papadia M, Herbort CP Jr. Early and sustained treatment modifies the phenotype of birdshot retinochoroiditis. Int Ophthalmol 2014; 33: 133-137.

27 Ikuno Y, Maruko I, Yasuno Y, Miura M, Sekiryu T, Nishida K et al. Reproducibility of retinal and choroidal thickness measurements in enhanced depth imaging and highpenetration optical coherence tomography. Invest Ophthalmol Vis Sci 2011; 52: 5536-5540.

28 Cervantes-Castañeda RA, Gonzalez-Gonzalez LA, CorderoComa M, Yilmaz T, Foster CS. Combined therapy of cyclosporine A and mycophenolate mofetil for the treatment of birdshot retinochoroidopathy: a 12-month follow-up. Br J Ophthalmol 2013; 97: 637-643.

This work is licensed under a Creative Commons Attribution-NonCommercialShareAlike 4.0 International License. The images or other third party material in this article are included in the article's Creative Commons license, unless indicated otherwise in the credit line; if the material is not included under the Creative Commons license, users will need to obtain permission from the license holder to reproduce the material. To view a copy of this license, visit http:// creativecommons.org/licenses/by-nc-sa/4.0/

(C) The Author(s) 2017 